\title{
Climate and monetary policy: do temperature shocks lead to inflationary pressures?
}

\author{
K. Mukherjee ${ }^{1} \cdot$ B. Ouattara ${ }^{2}$ (D) \\ Received: 7 October 2020 / Accepted: 18 June 2021/ Published online: 10 August 2021 \\ (C) The Author(s) 2021
}

\begin{abstract}
In the race towards economic growth, increased pollutant emissions have spurred the rise in global surface temperatures, intensifying the process of climate change. While the existing literature on the economic impact of climate-related variables has looked at outcomes such as growth, income, fiscal response, and poverty, the effect of temperature shocks on inflation has largely been neglected. This paper is an attempt to fill this lacuna. Indeed, we analyze the dynamic impact of temperature shocks on inflation, a key policy variable of most central banks. We use a panel-VAR method with fixed-effects and a sample of developed and developing countries over the period 1961-2014. Our results suggest that temperature shocks lead to inflationary pressures. Worryingly, and for developing countries in particular, we find that these effects persist several years after the initial shock. Our finding remained unaltered by various robustness checks. We show that these effects pose a threat to monetary policy making. We argue that central banks should pay more attention to temperature shocks.
\end{abstract}

Keywords Climate $\cdot$ Temperature shocks $\cdot$ Inflation $\cdot$ Monetary policy

\section{Introduction}

The vagaries of climate have spread a shriek of concern around the world. Increased losses in life and property due to floods, droughts, and other catastrophic events have been taking a heavy toll on the existence of mankind. The race towards higher economic growth has increased emissions of greenhouse gases into the atmosphere. This has led to the accumulation

\section{B. Ouattara}

osman.ouattara@manchester.ac.uk

K. Mukherjee

koyesha@gmail.com

1 Department for International Trade, London, UK

2 Global Development Institute, University of Manchester, Oxford Road, Manchester M13 9PL, UK 
of atmospheric concentrations of carbon dioxide, methane, and nitrous oxide, to the extent of degrading the environmental quality poorly. Their effects are "extremely likely" to have been the major cause of the observed global warming since the mid-twentieth century (IPCC 2014). Indeed, these concerns over the negative impact of climate change are shared among scientists as well as policy makers and civil societies globally. In fact, with global warming expected to worsen in coming years ${ }^{1}$, unless control policies are implemented, the future of our planet will be at stake. While the scientific impact of climate is undoubtedly well understood, its economic, social, and political impacts remain skeptically viewed. In relation to the latter, several studies have documented the detrimental effect of climate-related variables and natural disasters on growth and economic development (Bansal and Ochoa 2011; Dell et al. 2009, 2012; Hsiang and Jina 2014), on human wellbeing (Compeán 2013; Deschenes 2014; Banerjee 2015; Pugatch 2019), on peace and security (Burke et al. 2009; Homer-Dixon 1999; Devlin and Hendrix 2014; Fetzek and Mazo 2014; Milman and Arsano 2014; Reiling and Brady 2015; Feitelson and Tubi 2017; Dunlap and Fairhead 2014), and on migration (Perch-Nielsen et al. 2008; Marchiori et al. 2012; Beine and Parsons 2015; Rigaud et al. 2018). Additionally, the unprecedented heatwaves caused by the extreme temperature increases in Europe and North America in the summer of 2019, which experts have attributed to climate change, have led to more concerns about the impact of global warming.

While the existing literature on the economic impact of climate-related variables has looked at outcomes such as growth, income, fiscal response, and poverty, its effect on prices/inflation has generally been scarce. To be sure, a handful of studies have explored the link between natural disasters and prices. One of these studies is the work by Heinen et al. (2019) who find that floods and hurricane shocks lead to inflation in the context of 15 Caribbean countries. Parker (2018), on the other hand, shows that the impact of natural disasters on inflation depends on the type of disaster and the composition of inflation measure. Two other studies that have touched on the issue of natural disasters and prices are two case studies by Laframboise and Loko (2012) and Abe et al. (2014). Laframboise and Loko (2012), in a case study of seven countries, indicate that disasters appear to be associated with an increase in inflation in some countries. In contrast, Abe et al. (2014) find little increase in inflation following the Great East Japan Earthquake in 2011.

This paper is an attempt to contribute to the scant literature on the effect of climate-related variables on inflation. The paper makes the following two key contributions. First, unlike most of these studies that have generally focused on the effect of natural disasters, we investigate the specific effects of temperature shocks, and to our knowledge this is the first attempt to explore this link. In fact, while the effects of natural disasters are sudden and very often short-termed, temperature shocks tend to be silent in nature and persistent. Put differently, climate-related variables such as temperature are trend rather than cyclical phenomenon-which render difficult decisions about optimal monetary response (Breitenfellner et al. 2019). Bearing this in mind, studying the effect of temperature separately from that of natural disasters is sensible. The second contribution of the paper consists of linking its findings to monetary policy. Indeed, much of the debate today centers around the potential impact of climate change on financial stability, but very little is said about its implications for monetary policy.

Undoubtedly, investigating the effect of temperature shocks on inflation has important policy relevance. Central banks can "easily" manage demand-side shocks - because they are

\footnotetext{
${ }^{1}$ The report of the Intergovernmental Panel on Climate Change (IPCC) projects that global temperatures will increase by $2.8^{\circ} \mathrm{C}$ on average over the next century if no action is taken globally to address the issue.
} 
benign in nature. For example, expansionary demand shocks tend to push prices up as well as output. Because the price level and output are moving in the same direction, it is easier for monetary authorities to stabilize one without compromising the other. For example, the central bank can reduce inflation and at the same time insulate output from these demand shocks (Mankiw 2005). This situation is often referred to as "divine coincidence" because these shocks pull inflation, output, and employment in the same direction. In contrast, central banks tend to struggle vis-à-vis supply-side shocks such as temperature shocks. ${ }^{2}$ Indeed, unlike demand-side shocks, supply-side shocks tend to pull prices, output, and employment in opposite directions thereby requiring from monetary authorities - a trade-off between price stability and output stability. This is exacerbated in the context of climate-related variables (e.g., temperature shocks) where inflation is expected to increase and output reduced. ${ }^{3}$ Consequently, for a central bank following a pure inflation targeting, this would mean any attempt to forcefully bring down inflation will further reduce output because of the trade-off. Even considering a central bank that is not involved in an inflation targeting, attempts to reduce inflation induced by supply shocks, such as climate-related shocks, could be done at the cost of increasing the output gap.

To investigate the effect of temperature, we trace the dynamic response of inflation to temperature shocks for a sample of developed and developing countries over the period 19612014. Our results, based on a panel-VAR framework - which accounts for country fixedeffects - reveal that temperature shocks leads to inflationary pressures. Further, the results show that, in some cases, these effects - persistently-last over several years. Our finding remains robust to various robustness checks. We discuss the implications of the results for monetary policy making and argue that temperature shocks pose a serious threat to monetary policy making.

The remainder of the paper proceeds as follows. Section 2 discusses how temperature changes transmit to inflation. Section 3 presents the methodology and discusses the data. Section 4 presents the main results. Section 5 discusses the implications of our main finding for monetary policy making. Finally, Section 6 offers concluding remarks.

\section{How do temperature changes transmit to inflation?}

The question that begs to answer is, perhaps, how temperature shocks transmit to the conduct of monetary policy. To be sure, while the link between climate-related variables and fiscal policy, for example, is straightforward, its link with monetary policy is not clear cut. Temperature shocks could potentially affect prices and inflation in several ways, including a fall in agricultural output and changes in energy demand. Agriculture is highly sensitive to climate in terms of the average conditions of rainfall and temperature that determine the global distribution of food crops. A number of studies (see Rosenzweig and Parry 1994; Barrios et al. 2008; Mall et al. 2017) report quantitative evidence showing the damaging effect of climate change on agriculture. This cumulates into threats for food safety, harvest losses, and increase in the numbers of invasive species, pests, and diseases.

\footnotetext{
${ }^{2}$ The importance of such shocks in the choice of a monetary regime has long been emphasized in the monetary policy literature.

${ }^{3}$ Several empirical studies suggest that climate shocks contract output.
} 
Extreme weather events and climate change are also exacerbating the fragility of food production systems and the natural resource base. Related to this, temperature changes also impact on agricultural productivity which further contributes to food shortages. Consequently, food prices rise when there is an excess of demand over supply. The transfer of a shock (supply impacts of climate) translates into higher global food prices. Another channel through which temperature shocks can affect price stability is trade. For example, evidence suggests that higher temperatures lead to a reduction in productivity (see Deryugina and Hsiang 2014) and consequently the quantity of good exported, particularly, by poor countries (see for example, Gassebner et al. 2010 and Jones and Olken 2010) which could potentially affect market prices. Temperature shocks may also lead to higher prices when there is an increased demand for energy. In fact, simulations based on the International Model for Policy Analysis of Agricultural Commodities and Trade model suggest that inflation-adjusted prices of the world's three most important staple grains (maize, rice, and wheat) will increase $31-106 \%$ by 2050 due to climate (Nelson et al. 2010). Turning to energy, as climate becomes extreme (hotter or cooler), there will potentially be an increased demand for energy. Temperature shocks can also affect energy supply by reducing the productive efficiency of the infrastructure that produces the energy. Thus, an increased demand and a reduced supply of energy would lead to higher prices and increased inflation. What is more, climate also impacts negatively on fish stocks (Food and Agricultural Organization (2018a)) and livestock (Rojas-Downing et al. 2017), thereby leading to their shortage. This may again result in higher prices.

\section{Methodology and data discussion}

\subsection{Methodology}

To analyze the response of inflation to temperature shocks, we use the following reduced-form panel vector-auto-regression.

$$
y_{i, t}=\phi_{0}+B(L) y_{i, t-j}+\eta_{i}+\varsigma_{t}+\varepsilon_{i, t}
$$

where $y_{i, t}$, a $k$-dimensional vector, represents a vector of endogenous variables, $B(L)$ is the lag polynomial, $\phi_{0}$ a vector of constant, $\eta_{i}$ captures country-specific fixed-effects, $\varsigma_{t}$ are time specific trends, and $\varepsilon_{i, t}$ is a $k$-dimensional vector of reduced-form disturbances with $E\left[\varepsilon_{i, t}\right]=0$, $E\left[\varepsilon_{i, t}, \varepsilon_{i, s}^{\prime}\right]=0$ for $s \neq t$, and $E\left[\varepsilon_{i, t}, \varepsilon_{i, t}^{\prime}\right]=\sum_{\varepsilon}$. Finally, $i$ and $t$ represent, respectively, country and time subscripts.

To overcome the fact that the reduced-form disturbances will be generally correlated, one must transform model (1) into a structural model. This can be achieved by pre-multiplying Eq. (1) by $(k \times k)$ matrix $B_{0}$ as follows:

$$
B_{0} y_{i, t}=B_{0} \phi_{0}+B_{0} B(L) y_{i, t-j}+B_{0} \eta_{i}+B_{0} \varsigma_{t}+A_{0} \mu_{i, t}
$$

where $A \mu_{i, t}=B_{0} \varepsilon_{i, t}$ describes the relationship between the structural disturbance $\mu_{i, t}$ and the reduced-form disturbances $\varepsilon_{i, t}$. The structural disturbances are assumed to be uncorrelated with each other, thus implying that the variance-covariance matrix of the structural disturbances $\sum_{\mu}$ is diagonal. The contemporaneous relation among the variables in the vector of endogenous variables is captured by matrix $B_{0}$. 
The identification strategy adopted in this paper is based on the lower-triangular Choleski decomposition. Indeed, in this recursive approach, $A$ is restricted to a $k$-dimensional identity matrix and $B_{0}$ to a lower triangular matrix with unit diagonal. Consequently, the variancecovariance matrix of the structural disturbances, $\sum_{\mu}$, can be decomposed as $B_{0}^{-1} \sum_{\varepsilon}\left(B_{0}^{-1}\right)$ based on the Choleski decomposition $\sum_{\varepsilon}=V V^{\prime}$ by setting $B_{0}^{-1}=V D^{-1}$, with $\mathrm{D}$ being a diagonal matrix (with idenditical diagonal to $V$ ), and $\sum_{\mu}=D D^{\prime}$.

To trace out the effects of temperature shocks impulses on inflation, we implement a fivevariable specification. In choosing the endogenous variables for the VAR, we draw from the literature on monetary/government policy shocks and other studies that have employed the VAR method to explore the response of inflation (see for example, Christiano et al. 2005; Mallick and Sousa 2013). The set of endogenous variables consist of our proxy for climate (temperature), inflation (CPI), GDP ${ }^{4}$, government spending (G), and monetary aggregate (M2). The variables are entered into the vector [Climate, $G, G D P, C P I, M 2$ ]' and identification is based on a lower-triangular Choleski decomposition in line with this specific order. The main implication of this particular ordering or identification strategy is that we are allowing the variables in our model to have feedback effects. Furthermore, in this setting, temperature is not contemporaneously affected by all the other variables in the model, but responds to shocks to these variables with a lag effect which is a reasonable assumption. To be sure, economic activities will generally impact on greenhouse gas emissions which in turn will lead to a rise in temperature. It is also worth stressing that several studies (see Pindyck 2013; Stern 2016; Kahn et al. 2019; Schultz and Mankin 2019; Castle and Hendry 2020; Petris 2021; among others) have coined that climate-related variables, such as temperature, might not be, strictly, exogenous, as previous studies have assumed. Thus, modelling temperature shocks as endogenous, as it has been done here, is reasonable. Our ordering of the remaining variables follows existing works in the VAR/panel VAR literature (see for example Beetsma and Giuliodory 2011; Christiano et al. 2005; Mallick and Sousa 2013). However, it is worth stressing thatgiven our focus is only on temperature shocks - the impulse responses are not affected by this relative ordering of the other variables, as they all come after our climate variable (Christiano et al. 1999).

\subsection{Data}

We use annual data for a panel of 107 countries, which include 80 developing and 27 developed nations over the period 1961-2014. Our panel data is unbalanced. The data is drawn from various sources. The variables on inflation (CPI), real gdp (GDP), government spending (G), and money supply (M2) are taken from the World Bank, World Development Indicators Database (World Bank 2019). In terms of the measure for temperature, we use temperature change (TEMP). Data on temperature change has been obtained from the Climate database of the Food and Agricultural Organization of the United Nations (2018b). As an additional robustness check, we also use the population-weighted temperature (degrees-day) index proposed by Atalla et al. (2018). Table 7 and 8 (Appendix 2) provides a range of summary statistics. For the estimations, we use the log values of the variables to the variance characteristics of the variables in the model. ${ }^{5}$ Moreover, as noted by Fomby et al. (2011), using

\footnotetext{
${ }^{4}$ It is perhaps worth highlighting that GDP is composed of the main sectors of the economy including the agricultural sector.

${ }^{5}$ To avoid dropping negative values, some variables were rescaled without loss of generality.
} 
a $\log$ transformation also makes the interpretation of the unit root in the level variables straightforward.

\section{Results}

\subsection{Unit root and Lag selection results}

We start by presenting the unit root results in Table 1. Given the unbalanced nature of our panel dataset, we must adopt unit root tests that are designed for such data structure. For this reason, we use widely adopted panel unit root tests, namely the Levin et al. (2002) test (LLC), Im et al. (2003) (IPS) and the Fisher-type test (ADF-Fisher) proposed by Maddala and Wu (1999), and Choi (2001). ${ }^{6}$ The results suggest that for the variables, LCPI, LG, and LM2, the null hypothesis of a "unit root" is rejected by all the various tests, thus implying that these variables are stationary in levels. Turning to the variables LGDP and LTEMP, we observe some conflicting results. The LLC test shows that for LTEMP the null hypothesis of a "unit root" cannot be rejected while the IPS test reveals similar conclusion for LGDP. However, given that on balance the tests, overwhelmingly, reject the null, we conclude that these variables are stationary in level. In other words, the variables enter our VAR specifications in their level form.

Next, we choose the lag structure of the VAR. Given the annual frequency of the dataset, we follow existing empirical studies by setting the maximum lag to 2 . Then, we use the widely adopted Bayesian information criteria (BIC) and Akaike information criteria (AIC) to determine the optimal lag of the VAR. As can be seen in Table 2, the results for the lag selection appear to be mixed. Indeed, with the exception of the developed countries sample, the AIC and BIC suggest different optimal lag. In the face of this, we decided to choose a VAR (2) for our estimation. Nonetheless, we also replicate the exercise using a VAR (1) for robustness purpose.

\subsection{Main results}

For the results, we present the mean response of inflation to temperature shocks on the tables up to a 6-year time horizon. With respect to the impulse response graphs, we extend the time period to a 12-year time horizon. The Y-axis represents the mean responses, which are captured by the dark line on the figures. The pink lines represent the $95 \%$ confidence band intervals, obtained via Monte Carlo simulations (1000 replications). Results are obtained using the RATS Estima Software version 9.2. We start by exploring the effect of temperature shocks on inflation using the whole sample which comprises both developed and developing countries. ${ }^{7}$ The results are summarized in Table 3 while Figure 1 shows the ensuing impulse response functions. The results (in Table 3) show that on impact inflation increases significantly (in statistical terms) by $2.632 \%$ with a $1 \%$ change in temperature. Although this effect dies down slowly, it remains significant up to 4 years after the initial shock before becoming

\footnotetext{
${ }^{6}$ Unit root tests that deal with cross-sectional dependence, e.g., Pesaran (2007); Pesaran and Co 2019, require a strongly balanced panel.

${ }^{7}$ For the sake of space, we only report the results related to inflation, our variable of interest. Full set of results related to the other variables in our model are available upon request.
} 
Table 1 Panel unit root tests

\begin{tabular}{llll}
\hline Variables & LLC & IPS & ADF-Fisher \\
& T-Stat & W-Stat & Chi-square \\
\hline LCPI & $-12.533^{* * *}$ & $-2.703 * * *$ & $279.072 * * *$ \\
LG & $-6.933^{* * *}$ & $-7.543 * * *$ & $380.587 * * *$ \\
LGDP & $-11.144 * * *$ & 4.081 & $351.002 * * *$ \\
LM2 & $-2.123^{* *}$ & $-3.238^{* * *}$ & $213.252 *$ \\
LTEMP & 5.143 & $-6.716^{* * *}$ & $383.860 * * *$ \\
\hline
\end{tabular}

Note: (a) Null hypothesis: unit root. (b) *; **; and *** denote, respectively, 10; 5; and 1\% significance level. (c) Constant included (inclusion of linear trends shows similar outcome).

insignificant. The graphical representations of the mean estimates are shown in Figure 1 which captures the impulse response functions over a 12-year time horizon.

The above analysis assumes some homogeneity across the countries in our sample. However, this assumption is more likely to be unrealistic as the sample includes both developed and developing countries. In the next step, we relax this assumption and split our sample into developed and developing countries. A priory, it is expected that countries with stronger economic backgrounds may experience a milder impact owing to their advanced financial and technological settings.

Starting with the results of developed countries, which are summarized by Table 4 and the corresponding IFRs represented by Figure 2, it can be seen that the instantaneous response of inflation is positive (an increase $2.439 \%$ ) and statistically significant. However, this effect dies out quickly and becomes insignificant after 1 year. In contrast, developing countries depict a different picture. Figure 3 portrays the impulse responses to a $1 \%$ shock in temperature, while Table 5 provides the outcomes for specific moments after the shock. Indeed, on impact inflation rises significantly by $2.703 \%$. However, unlike in the context of developed countries, this effect remains significant up to 6 years after the initial impact.

\subsubsection{Robustness checks}

In addition to splitting our sample, as above, we also perform various robustness checks. We only report the IFRs due to space limitations. First, we re-run the above specifications this time using an optimal lag 1. As can be seen from Appendix Figs. 4, 5, and 6, which portray, respectively, the IFRs the whole, developed countries, and developing countries samples, the results are quantitatively and statistically similar to our previous results. Second, we drop outliers from our samples. More specifically we exclude countries with hyperinflation over the sample period. Indeed, looking at the experience of countries with hyperinflation, existing information suggests that around 28 countries have experienced this phenomenon. Among

Table 2 VAR lag selection

\begin{tabular}{lll}
\hline Sample & AIC-lag selection & BIC-lag selection \\
\hline Whole & 1 & 2 \\
Developed & 2 & 2 \\
Developing & 1 & 2 \\
\hline
\end{tabular}


Table 3 Dynamic response of inflation to temperature shocks (whole sample)

\begin{tabular}{ll}
\hline Timing of shock & Inflation \\
\hline Instantaneous response & $2.632^{* * *}$ \\
& {$[2.5742 .696]$} \\
1 year after shock & $0.233^{* *}$ \\
& {$[0.1490 .320]$} \\
2 years after shock & $0.123^{* *}$ \\
& {$[0.0430 .205]$} \\
3 years after shock & $0.024^{* *}$ \\
4 years after shock & {$[0.0070 .043]$} \\
5 years after shock & $0.009^{* *}$ \\
& {$[0.0010 .021]$} \\
6 years after shock & 0.003 \\
& {$[-0.0020 .009]$} \\
\hline
\end{tabular}

Notes: (a) ** indicate statistical significance at 5\% levels; (b) [] represent 95\% confidence band; (c) Monte Carlo simulations.

these 28 countries, five turned out to be in our sample. ${ }^{8}$ We drop these countries from the whole sample and in the sample of developing countries, and replicate the same exercise as in our main results. ${ }^{9}$ The IFRs are shown in Appendix Figs. 7 and 8 (Appendix 1), respectively, for the whole sample and the developing countries sample. As it is clear from the IFRs, the results are roughly unchanged. In the third additional robustness check, we drop periods that are considered as unusual due to various shocks. These shocks include the two oil shocks and the relatively recent global financial crisis. ${ }^{10}$ To be more specific, we focus on the 1980-2005 period. The IFRs are depicted in Appendix Figs. 9, 10, and 11, respectively, for the whole, developed, and developing countries sample. Again, the main finding that temperature shocks lead to inflation is confirmed.

In the above exercises, in line with standard practice in panel data analysis, fixed-effects were included to control for all time-invariant differences between the countries in our samples. However, it has recently been argued (see Schlenker 2010; Kolstad and Moore 2019) that in the context of climate-related variables this may be problematic, particularly when using annual data - as in our case. This is because, under this setting, one would be capturing temporary and unexpected shocks (Schlenker 2010). This implies that any quantification of the impact of climate (related variables) will only be capturing its short-run effects (Kolstad and Moore 2019). For this purpose, we replicate our main results without the fixedeffects. Figures S1A to S1C (see Supplementary Material) show the impulse response functions. Overall, the results confirm our main finding that temperature shocks result to increases in inflation. However, it is worth stressing that, while removing the fixed-effects does not alter the main finding, there are some clear patterns emerging in terms of the persistence of the initial shock. To be more precise, in the context of the developed country sample, the results are almost similar to the previously reported results; however, for the whole and the

\footnotetext{
${ }_{8}$ These countries are Bolivia, Brazil, Congo, Democratic Republic Congo, and Peru.

${ }^{9}$ Given that these countries are in the developing world, we do not replicate this robustness check for the developed countries sample.

${ }^{10}$ It is worth noting that in our various specifications we did include time dummies to capture such shocks.
} 


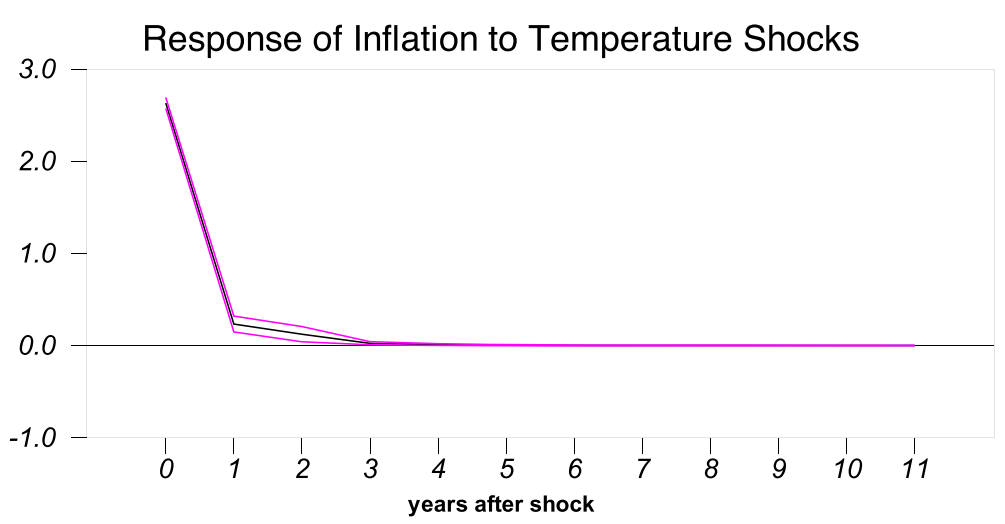

Figure 1 Dynamic response of inflation to temperature shocks (whole sample)

developing country samples, it can be observed that it now takes up to 8 years for the initial shock to die.

Next, we consider an alternative measure of temperature, derived from the Degree-days methodology. Indeed, we replicate our main results using a population-weighted temperature data proposed by Atalla et al. (2018) who constructed several thermal indicators for a large sample of countries. For our purpose, the temperature Degree-days appears to be the most relevant. We employ both the Heated Degree-days (HDD) and the Cooling Degree-days (CDD). The authors calculated these measures as follows:

$$
D D_{i}=\sum_{0 \text { days }}^{i \text { days }}\left(T_{\text {ref }}-T_{\text {daily mean }}\right)
$$

where $D D$ stands for Degree-days, $T_{\text {ref }}$ is a reference temperature, and $T_{\text {daily mean }}$ is the average between the minimum and maximum temperature. If $D D_{i}>0$ then it is counted as $H D D$ and if $D D_{i}$ $<0$ then it represents $C D D$. The reference temperature was set at $65^{\circ} \mathrm{F}\left(18^{\circ} \mathrm{C}\right)$. The HDD and CDD, which are related to outside air temperature, are generally used to proxy for the intensity and duration

Table 4 Dynamic response of inflation to temperature shocks (developed countries)

\begin{tabular}{ll}
\hline Timing of shock & Inflation \\
\hline Instantaneous response & $2.439 * *$ \\
& {$[2.3182 .583]$} \\
1 year after shock & 0.081 \\
& {$[-0.1130 .275]$} \\
2 years after shock & 0.148 \\
& {$[-0.0380 .337]$} \\
years after shock & 0.012 \\
4 years after shock & {$[-0.0310 .062]$} \\
5 years after shock & 0.017 \\
& {$[-0.0100 .056]$} \\
6 years after shock & 0.003 \\
& {$[-0.0140 .024]$} \\
\hline
\end{tabular}

Notes: (a) ** indicate statistical significance at 5\% levels; (b) [] represent 95\% confidence band; (c) Monte Carlo simulations. 


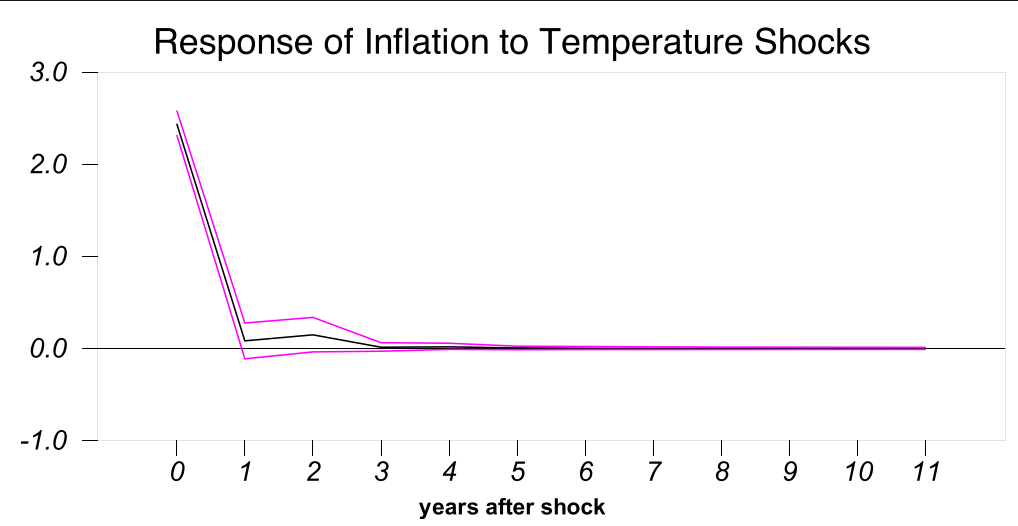

Figure 2 Dynamic response of inflation to temperature shocks (developed countries)

of cold and hot climates (Atalla et al., 2018). The HDD and CDD were "created through a combination of gridded atmospheric dataset developed by the National Oceanographic Atmospheric Agency" (Atalla et al. 2018, p. 1049). The Degree-days have then been convoluted with the Columbia University's gridded population of the world dataset (GPW v.3) and the UNEP/GRIDSioux Falls regional datasets to create the population-weighted temperature indices, using an enhanced spatial resolution of $1.6^{\circ} \times 1.6^{\circ}$. The summary statistics in Table 7 and 8 (Appendix 2) suggest that the average CDD is 6316.907 and the average HDD is 4896.223 , thus, implying that the annual variation in HDD is lower than that of CDD. A unit increase in the HDD or the CDD corresponds to an increase of $1{ }^{\circ} \mathrm{C}, 1$ day. ${ }^{11}$ Due to space limitation, we only report the results related to the HDD. ${ }^{12}$ The corresponding impulse response functions, for the HDD, are captured by Figures S2A to S2C (Supplementary Material). Overall, the results confirm our finding that temperature shocks lead to inflationary pressures. Nonetheless, it is worth noting that with the use of the HDD (population-weighted temperature), the effect of temperature shocks on inflation remains worryingly persistent several years after the initial shock for all three samples. These results are in clear contrast with existing studies on the effect of natural disasters on inflation. These studies, generally, find a short-term effect of natural disasters on inflation.

Finally, we replicate our main results, but this time including rainfall as an additional variable in our model. The ensuing impulse response functions for the whole sample and developed and developing countries are portrayed in Figures S3A to S3C (Supplementary Material), respectively. Overall, the results remain in line with our main findings.

\section{Implications for monetary policy}

On the one hand, the evidence provided in this study robustly shows that temperature shocks generate inflationary pressures whether in developed or developing countries, and these effects can be persistent over several years depending on the sample and measure of temperature used. On the other hand, one key objective of central banks around the world is to ensure price stability and, relatively, low inflation. This conviction has its root in the theoretical and

\footnotetext{
${ }^{11}$ Atalla et al. (2018) provide detail on the calculation of the HDD and CDD.

12 The results based on the $C D D$ exhibit similar patterns so we do not report them here but are available upon request.
} 


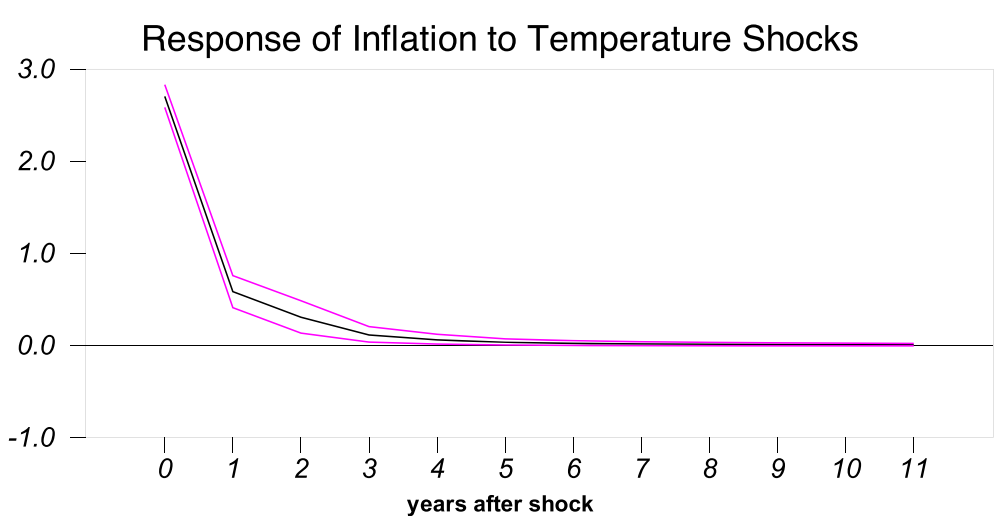

Figure 3 Dynamic response of inflation to temperature shocks (developing countries)

empirical view that price stability is a sine qua non for achieving high growth. The question is whether climate-related variables such as temperature shocks could undermine central banks' ability in achieving this objective. To explore this, let us consider the Taylor rule which has generally been used to depict central banks' reaction function. The optimal policy rule can be formulated as:

$$
i_{t}=r+\pi^{*}+\phi_{\pi}\left(\pi_{t}-\pi^{*}\right)+\phi_{y}\left(y_{t}-y_{t}^{*}\right)
$$

$i_{t}$ denotes the nominal interest rate; $r$ is the real interest rate, $\pi_{t}$ is the actual inflation, and $\pi^{*}$ its target rate - thus, $\left(\pi_{t}-\pi^{*}\right)$ can be described as the inflation-gap; the term $\left(y_{t}-y_{t}^{*}\right)$ represents the output gap; the $\phi s$ determine how forcefully central banks respond to deviations. As a matter of fact, it is worth noting that the Taylor rule has been derived traditionally from empirical examination of the central banks successful behavior in achieving and maintaining macroeconomic stability (Piergallini and Rodano 2017). The "Taylor principle," which follows from this rule, suggests that response of the nominal interest rate to changes in inflation is more than one-to-one. Several empirical studies have offered support for the "Taylor principle" (see for example, Woodward 2001; Bullard and Mitra 2002; Gali 2008).

Table 5 Dynamic response of inflation to temperature change shocks (developing countries)

\begin{tabular}{lc}
\hline Timing of shock & Inflation \\
\hline Instantaneous response & $2.703 * *$ \\
& {$[2.5842 .830]$} \\
1 year after shock & $0.584 * *$ \\
& {$[0.4100 .758]$} \\
2 years after shock & $0.305^{* *}$ \\
3 years after shock & {$[0.1330 .485]$} \\
4 years after shock & $0.112^{* *}$ \\
5 years after shock & {$[0.0360 .204]$} \\
6 years after shock & $0.059^{* *}$ \\
& {$[0.0150 .121]$} \\
& $0.033^{* *}$ \\
& {$[0.0040 .071]$} \\
& $0.022^{* *}$ \\
\hline
\end{tabular}

Notes: (a) ** indicate statistical significance at 5\% levels; (b) [] represent 95\% confidence band; (c) Monte Carlo simulations. 
Let us start by focusing on the inflation gap. According to Eq. (4), the central bank will adjust the interest rate to ensure that price stability and inflation remain under control. Consequently, given that the findings in this paper suggest that temperature shocks lead to increases in inflation rates, this implies that one may observe high deviations between the actual and the targeted rate of inflation. As a result, one would expect the central bank to react in such a scenario by altering considerably (increasing in the present context) the interest rate to maintain its goal. Considering the case of a central bank that is operating under a strict inflation targeting, for example, any deviations from the target inflation rate would trigger changes in interest rate. However, if the effect of temperature shocks on inflation remains persistent — over several years - as some of the results show, an inflation targeting central bank may be faced with a longer term challenge, in trying to achieve its inflation target. To complicate things further, as the "Taylor principle" suggests, the increase in inflation will be met with more than a one-to-one increase in the interest rate. Even for central banks engaged in flexible inflation targeting, whereby interest rates are temporary adjusted to stabilize the economy, these persistent climate-induced inflationary pressures could be challenging. In fact, persistently increasing the nominal interest rate, to control inflation, can generate further inflation because it corresponds to an increase in the inflation target (Reis 2018). Also, it is worth noting that big changes in interest rates may have ramifications for the wider economy. If the central bank responds to deviations by increasing the interest rate, this could increase borrowing costs and thus affect firms and households in two ways. First, the existing borrower will see their debt burden increased and firms that planned to invest will potentially postpone their investment plans. Second, the increase in inflation may also trigger increases in other prices and wages. Third, textbook macroeconomics tells us that increases in the interest rate will lead to capital inflows which in turn might put pressures on the exchange rate to appreciate. All these effects would not only have ramifications for monetary authorities' ability in diagnosing malfunctions in the economy but also for their forecasting ability.

Another challenge for central banks is that the shocks generated by climate-related variables are categorized as supply shocks, which are challenging for central banks. Indeed, as aforementioned, these shocks would require the central bank to make a trade-off between increasing output and reducing inflation. To explore this, we look at how output responds to temperature shocks in the current context. Table 6 summarizes the main results. As can be seen from the results, in all three cases, temperature shocks lead to a contraction in output. However, only in the context of developing countries that these effects are statistically significant. ${ }^{13}$ These results suggest that in the case of developed countries there are less concerns about the trade-off between increasing output and reducing inflation. These countries will only have to be concerned with the inflationary pressures generated by temperature shocks. In contrast, developing countries face a different scenario. Indeed, in addition to their inflationary effects, temperature shocks also lead to output contraction. As discussed earlier, a central bank - with dual mandate - will face the challenge of stimulating economic activities or reduce inflation. If increasing output is the primary objective, then it would have to endure some inflation. On the other hand, if reducing inflation is fundamental then it would have to accept the decline in output. Striking the right balance between these two policy objectives has been a challenge for central bankers. Even if output growth is not an explicit objective of a central bank, the state of the economy (a recession or a widening output gap example) has ramifications for inflation and thus requires a monetary policy response.

${ }^{13}$ The IFRs, not presented here due to space limitation, show that these effects remain statistically significant over the 12-year time horizon. 
Table 6 Effect of temperature shocks on output

\begin{tabular}{|c|c|c|c|}
\hline Timing of shock & Whole sample & Developed countries & Developing countries \\
\hline Instantaneous response & $\begin{array}{l}-0.002 \\
{\left[\begin{array}{lll}-0.017 & 0.015\end{array}\right]}\end{array}$ & $\begin{array}{l}-0.001 \\
{\left[\begin{array}{ll}-0.003 & 0.001\end{array}\right]}\end{array}$ & $\begin{array}{l}-0.004 \\
{\left[\begin{array}{ll}-0.027 & 0.020\end{array}\right]}\end{array}$ \\
\hline 1 year after shock & $\begin{array}{l}-0.015 \\
{\left[\begin{array}{lll}-0.036 & 0.007]\end{array}\right]}\end{array}$ & $\begin{array}{l}-0.001 \\
{\left[\begin{array}{ll}-0.004 & 0.003\end{array}\right]}\end{array}$ & $\begin{array}{l}-0.022 \\
{\left[\begin{array}{ll}-0.052 & 0.007]\end{array}\right]}\end{array}$ \\
\hline 2 years after shock & $\begin{array}{l}-0.0168 \\
{\left[\begin{array}{lll}-0.037 & 0.004]\end{array}\right]}\end{array}$ & $\begin{array}{l}-0.003 \\
{\left[\begin{array}{ll}-0.009 & 0.003\end{array}\right]}\end{array}$ & $\begin{array}{l}-0.027 \\
{\left[\begin{array}{lll}-0.056 & 0.001]\end{array}\right]}\end{array}$ \\
\hline 3 years after shock & $\begin{array}{l}-0.0172 \\
{\left[\begin{array}{lll}-0.036 & 0.002\end{array}\right]}\end{array}$ & $\begin{array}{l}-0.003 \\
{\left[\begin{array}{ll}-0.004 & 0.008\end{array}\right]}\end{array}$ & $\begin{array}{l}-0.0283 * * \\
{[-0.056-0.002]}\end{array}$ \\
\hline 4 years after shock & $\begin{array}{l}-0.0167 \\
{\left[\begin{array}{ll}-0.035 & 0.001\end{array}\right]}\end{array}$ & $\begin{array}{l}-0.004 \\
{\left[\begin{array}{ll}-0.014 & 0.004\end{array}\right]}\end{array}$ & $\begin{array}{l}-0.028 * * \\
{[-0.054-0.003]}\end{array}$ \\
\hline 5 years after shock & $\begin{array}{l}-0.016 \\
{\left[\begin{array}{ll}-0.033 & 0.001\end{array}\right]}\end{array}$ & $\begin{array}{l}-0.005 \\
{\left[\begin{array}{ll}-0.033 & 0.001\end{array}\right]}\end{array}$ & $\begin{array}{l}-0.027 * * \\
{[-0.052-0.003]}\end{array}$ \\
\hline 6 years after shock & $\begin{array}{l}-0.015 \\
{\left[\begin{array}{ll}-0.031 & 0.001\end{array}\right]}\end{array}$ & $\begin{array}{l}-0.005 \\
{\left[\begin{array}{ll}-0.016 & 0.005\end{array}\right]}\end{array}$ & $\begin{array}{l}-0.026 * * \\
{[-0.050-0.003]}\end{array}$ \\
\hline
\end{tabular}

Notes: (a) ** indicate statistical significance at 5\% levels; (b) [] represent 95\% confidence band; (c) Monte Carlo simulations.

All in all, it is clear that temperature shocks, by inducing inflationary pressures, pose a threat to monetary policy making and specifically affects central bank's ability to achieve their key objectives of low inflation/price stability and stimulate economic activity (output). Additionally, given that climate-related variables are not accommodated in most central banks' objective functions, attempts to diagnose sources of malfunction of the economy could prove fruitless. For example, it is important to understand the sources of inflation pressures so that monetary policy can respond accordingly. Put differently, unless the central bank knows the root cause of inflation, they will be trying to catch up with headline inflation and therefore, implement the wrong type of policy response. Related to this, there is also the potential that their forecasting ability would be undermined. And, if forecast errors are large enough, they could result in the wrong policy decisions with irreversible consequences (Buddhari and Chensavasdijai 2003). Further, climate-related variables such as temperature shocks are trend rather than cyclical, which complicates matters for central banks in terms of achieving an optimal monetary policy response (Breitenfellner et al. 2019). Moreover, unlike other climaterelated events such as natural disasters that occur at a point in time and generally generate short-term effects, the inflationary effects of temperature shocks are generally continuous and persistent and can last over several years. This could prove challenging for policy makers for reasons discussed earlier. Also, given that one would expect lags in monetary policy reaction, the presence of persistent inflation effects can undermine central bankers' credibility in terms of implementing the right policy response.

In light of this threat of temperature shocks to the ability of central banks to conduct efficient monetary policy, the question is what policy tools can be used to mitigate these effects? Ideally, temperature shocks are supply shocks, and monetary authorities can use any of the traditional methods used for these types of shocks. However, unlike other supply shocks that are easily identifiable, temperature shocks behave like a "silent disease." And the fact that central banks for long have remained unconcerned about climate-related issues makes the effects of temperature shocks even more worrying. Nevertheless, central banks could implement policies to mitigate their effects. First, it is crucial that central banks pay more attention to temperature shocks. Indeed, in order to implement the right policy response, it is important to understand the sources of inflationary pressures. This is even imperative in the current context where these shocks contract output and 
persistently increase inflation. In practical terms, this would require central banks to accommodate temperature-related shocks into their decision-making process, objective function, and particularly when forecasting inflation and other macroeconomic variables. Second, given that the evidence suggests that temperature changes are a threat to monetary policy making, central banks could implement green monetary policies or green financing towards slowing or reversing the trends in temperature changes. Broadly, these policies could center around traditional tools such as differentiated rediscount rates and reserve requirement to encourage green lending from financial institutions. Another policy instrument could be through green quantitative easing where central banks would engage in large-scale purchase of green financial assets from financial institutions via open markets operations.

\section{Conclusion}

This study investigated the impact of climate change on inflation for a panel of developed and developing countries over the period 1961-2014. Using panel VAR analysis, our results suggest that climate change leads to inflationary pressures in both developed and developing countries. Worryingly, some of our results show that the dynamic response of inflation to climate change is persistent even several years after the initial shock. We argued that climate change poses a serious threat to central banks in their attempt to achieve their key objective of maintaining low inflation and price stability. A key policy lesson coming out of this work is that central banks should pay attention to the effects of temperature changes. Indeed, they should take into account these effects in their objective function and their forecasting exercises. They may also seek to implement further policies to reverse the trends observed in temperature changes.

A useful extension of this work would be to look at how climate affects financial stability. At the conceptual or theoretical level, at least, there seems to be some agreement that climate and related mitigation policies have severe implications for global financial stability. Another extension of this work would be to explore whether financial institutions' activities contribute to climate anomalies. For example, it might be interesting to know the impact of private credit on climate-related variables.

\section{Appendix 1}

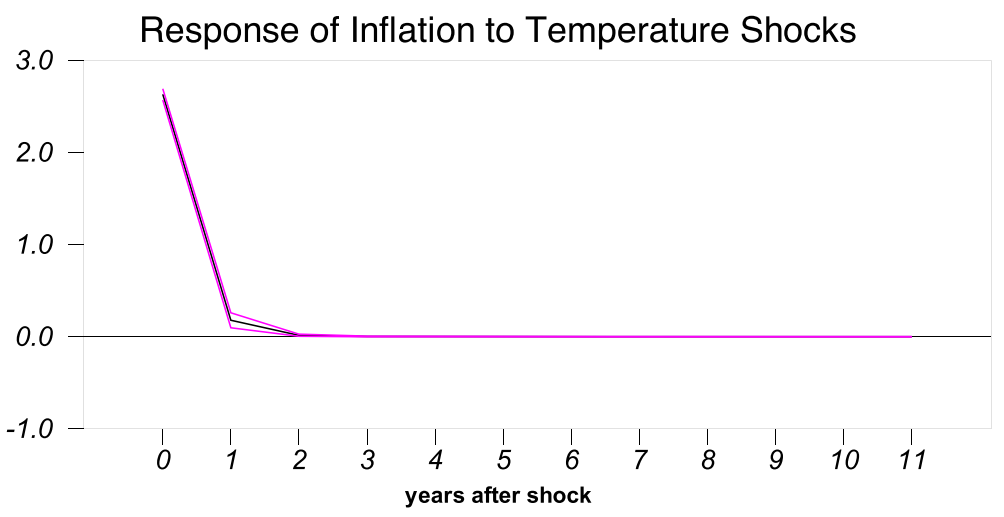

Figure 4 Dynamic response to climate shocks (whole sample)-lag 1 


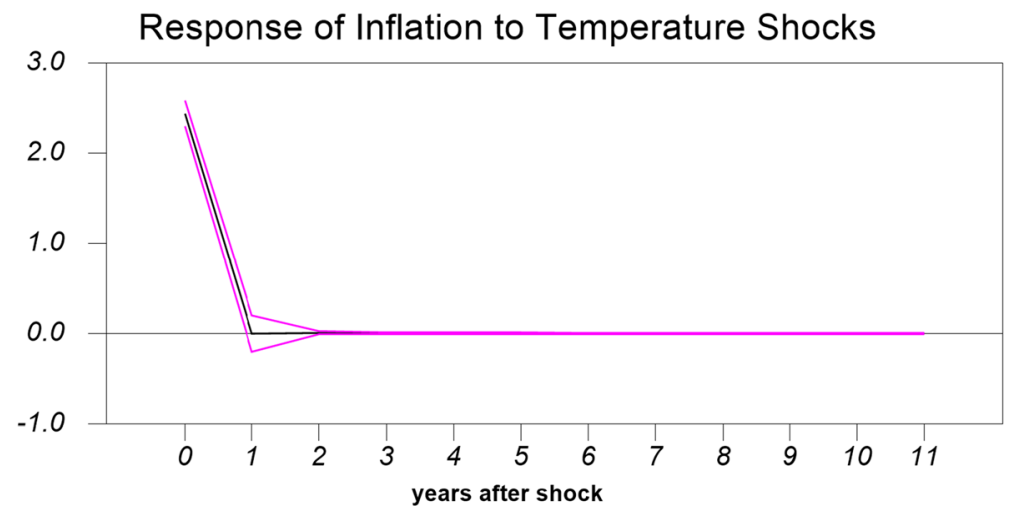

Figure 5 Dynamic response to climate shocks (developed countries sample) - lag 1

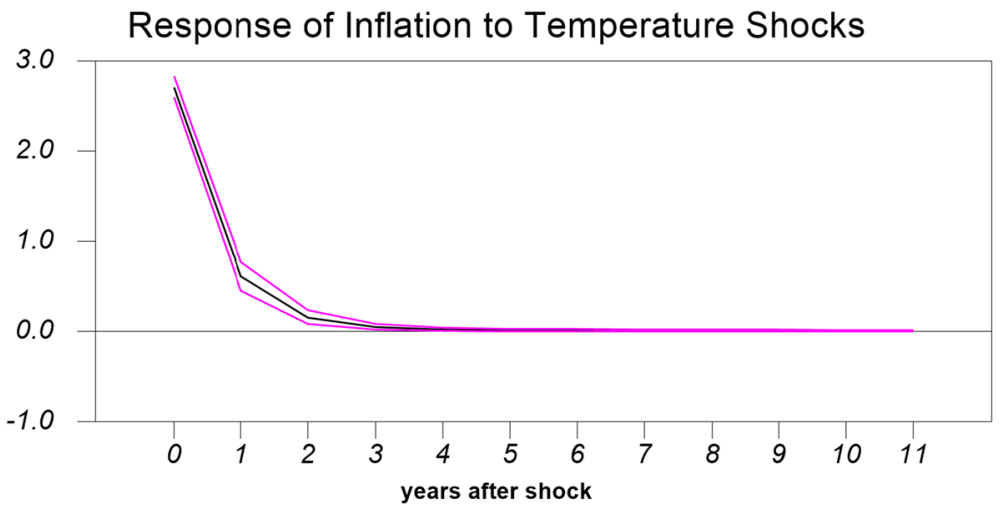

Figure 6 Dynamic response to climate shocks (developing countries sample)—-lag 1

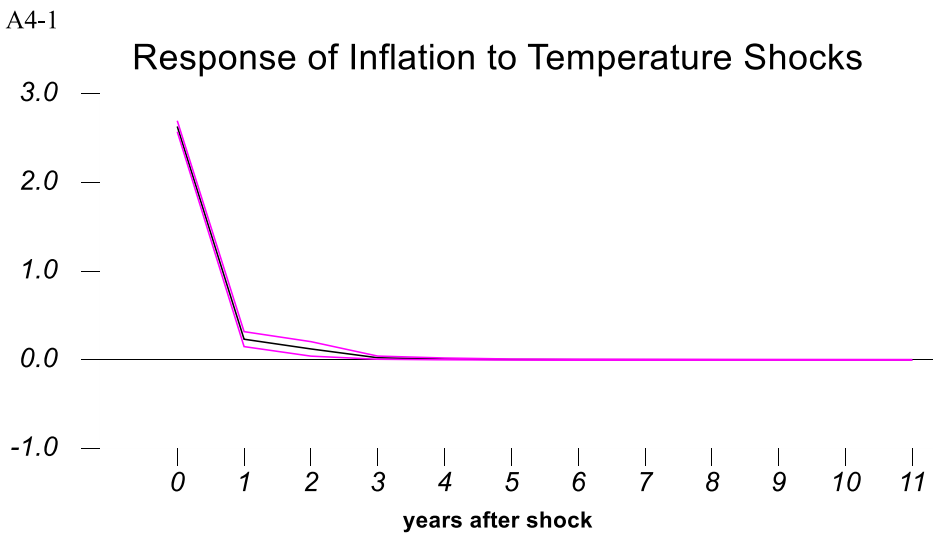

Figure 7 Dynamic response to climate shocks (whole sample)—outliers dropped 


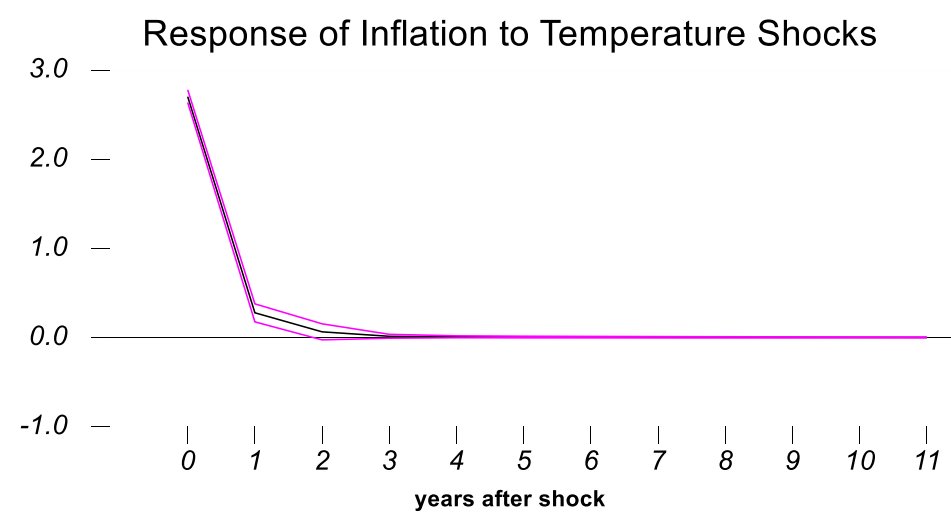

Figure 8 Dynamic response to climate shocks (developing countries sample)_outliers dropped

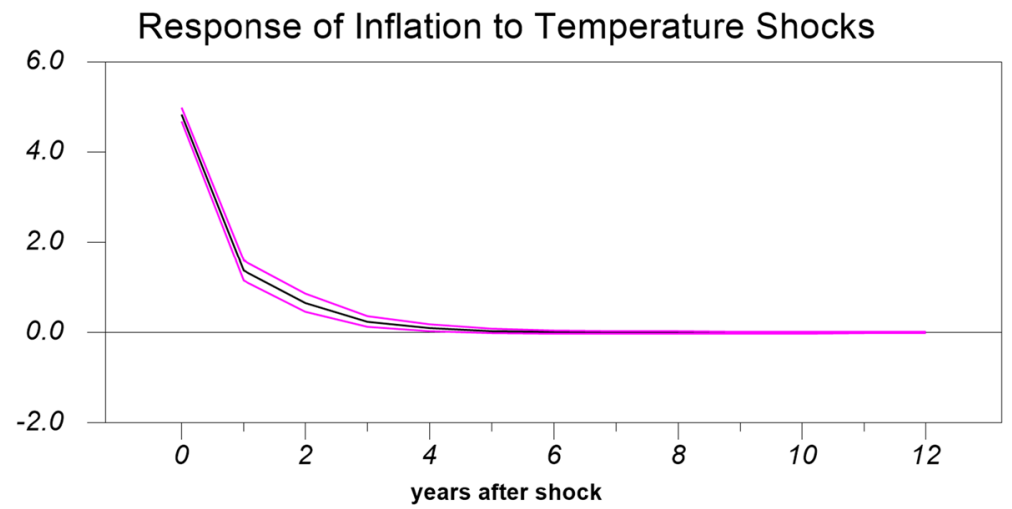

Figure 9 Dynamic response to climate shocks (whole sample)—subperiod

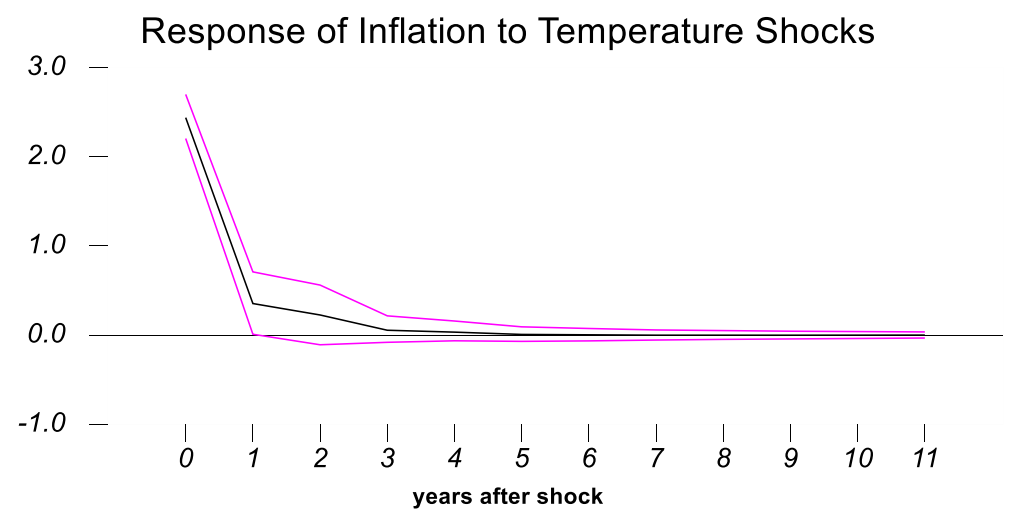

Figure 10 Dynamic response to climate shocks (developed countries sample) — subperiod 


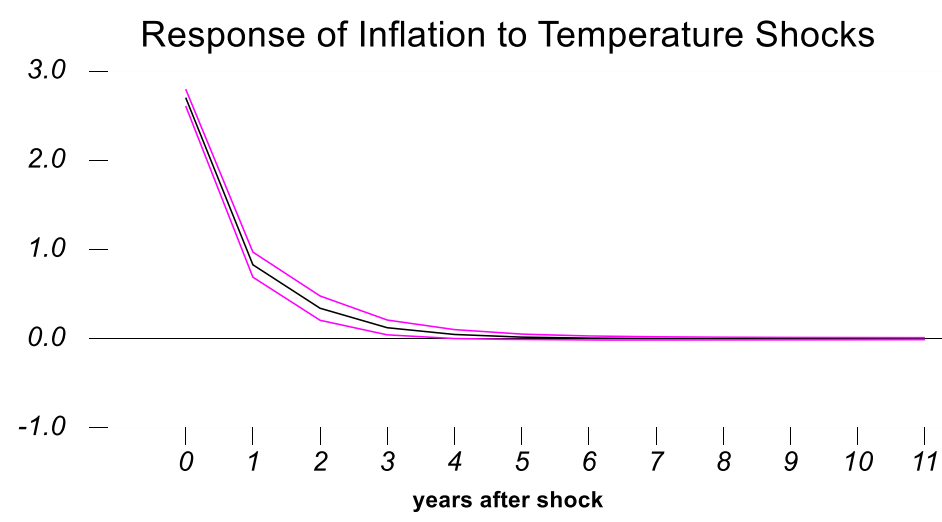

Figure 11 Dynamic response to climate shocks (developing countries sample) - subperiod

\section{Appendix 2}

Table 7 Summary statistics

\begin{tabular}{lllll}
\hline Variable & Mean & SD & Min & Max \\
\hline CPI & 47.383 & 38.411 & $1 \times 10^{-10}$ & 250.829 \\
Temp & 0.382 & 0.546 & -1.777 & 2.985 \\
Rainfall & 1226.93 & 869.98 & 10.92 & 4999.69 \\
Population-weighted temperature index (HDD) & 4896.223 & 5998.599 & 0 & 25692 \\
Population-weighted temperature index (CDD) & 6316.907 & 4220.963 & 3 & 16473 \\
GDP (billions of USD 2011 prices) & 347 & 1210 & 0.1 & 17000 \\
G (\% GDP) & 16.290 & 8.661 & 2.332 & 163579 \\
M2 (\% GDP) & 45.745 & 36.267 & 2.857 & 361.641 \\
\hline
\end{tabular}


Table 8 List of countries

Developing countries

\begin{tabular}{|c|c|c|}
\hline Algeria & Haiti & Papua New Guinea \\
\hline Bahrain & Honduras & Paraguay \\
\hline Bangladesh & India & Peru \\
\hline Barbados & Indonesia & Philippines \\
\hline Belize & Iran & Qatar \\
\hline Bhutan & Iraq & Samoa \\
\hline Bolivia & Jordan & Saudi Arabia \\
\hline Botswana & Kenya & Senegal \\
\hline Brazil & Kuwait & Seychelles \\
\hline Burkina Faso & Lao PDR & Solomon Islands \\
\hline Cameroon & Lesotho & South Africa \\
\hline Chad & Libya & Sri Lanka \\
\hline China & Madagascar & Suriname \\
\hline Colombia & Malawi & Swaziland \\
\hline Congo & Malaysia & Syrian Arab Republic \\
\hline Costa Rica & Mali & Tanzania \\
\hline Cote d'Ivoire & Mauritania & Thailand \\
\hline Democratic Republic of the Congo & Mauritius & The Bahamas \\
\hline Ecuador & Mexico & The Gambia \\
\hline Egypt & Morocco & Togo \\
\hline El Salvador & Mozambique & Tonga \\
\hline Equatorial Guinea & Myanmar & Tunisia \\
\hline Fiji & Nepal & Turkey \\
\hline Gabon & Niger & Uruguay \\
\hline Ghana & Nigeria & Vanuatu \\
\hline Guatemala & Pakistan & Zambia \\
\hline Guinea-Bissau & Panama & \\
\hline \multicolumn{3}{|l|}{ Developed countries } \\
\hline Australia & Italy & \\
\hline Austria & Japan & \\
\hline Canada & Malta & \\
\hline Cyprus & Netherlands & \\
\hline Denmark & New Zealand & \\
\hline Finland & Norway & \\
\hline France & Portugal & \\
\hline Germany & Spain & \\
\hline Greece & Sweden & \\
\hline Iceland & Switzerland & \\
\hline Ireland & UK & \\
\hline Israel & USA & \\
\hline
\end{tabular}

Supplementary Information The online version contains supplementary material available at https://doi.org/ 10.1007/s10584-021-03149-2.

Acknowledgements The authors would like to thank three anonymous reviewers for helpful comments. We also would like to thank Massimo Giuliodori for sharing the RATS code used for the estimations. Finally, we are indebted to J. Atsu Amegashie, Joshy Easaw, and participants at a UNU-WIDER seminar (in March 2020) for their thoughtful suggestions.

Data availability The data will be provided as supplementary material. 
Code availability The Rats code will be made available with the permission of the original authors of the code.

\section{Declarations}

Conflict of interest The authors declare no competing interests.

Open Access This article is licensed under a Creative Commons Attribution 4.0 International License, which permits use, sharing, adaptation, distribution and reproduction in any medium or format, as long as you give appropriate credit to the original author(s) and the source, provide a link to the Creative Commons licence, and indicate if changes were made. The images or other third party material in this article are included in the article's Creative Commons licence, unless indicated otherwise in a credit line to the material. If material is not included in the article's Creative Commons licence and your intended use is not permitted by statutory regulation or exceeds the permitted use, you will need to obtain permission directly from the copyright holder. To view a copy of this licence, visit http://creativecommons.org/licenses/by/4.0/.

\section{References}

Abe N, Moriguchi C and Inakura N (2014) The effects of natural disasters on prices and purchasing behaviors: the case of the Great East Japan Earthquake. Institute of Economic Research, Hitotsubashi University. Research Center for Economic and Social Risks, DP14-1. Accessed at: http://hermes-ir.lib.hit-u.ac.jp/ hermes/ir/re/26845/dp14-1.pd

Atalla T, Guardi S, Lanza A (2018) A global degree days database for energy related applications. Energy 143: $1048-1555$

Banerjee L (2015) Of disasters, status, and health. Rev Black Polit Econ 42(1-2):111-133

Bansal R and Ochoa M (2011) Temperature, aggregate risk, and expected returns. NBER Working Paper 17575. Accessed at: https://www.nber.org/papers/w17575

Barrios S, Ouatara B, Strobl E (2008) The impact of climatic change on agricultural production: is it different for Africa? Food Policy 33(4):287-298

Beetsma R, Giuliodory M (2011) The effects of government purchase shocks; review and estimates for the EU. J Econ 121(550):F4-F32

Beine M, Parsons C (2015) Climatic factors as determinants of international migration. Scand J Econ 117:723767

Breitenfellner A, Pointer W, Schubberth H (2019) The potential contribution of central banks to green finance. Q J Econ Res 88:55-72 DIW Berlin. Accessed February 2019

Buddhari A and Chensavasdijai V (2003) Inflation dynamics and its implications for monetary policy. Bank of Thailand Symposium Paper 2003

Bullard J, Mitra K (2002) Learning about monetary policy rules. J Monet Econ 49:1105-1129

Burke MB, Miguel E, Satyanath S et al (2009) Warming increases the risk of civil war in Africa. Proc Natl Acad Sci 106(49):20670-20674

Castle JL, Hendry DF (2020) Climate econometrics: an overview. Found Trends Econ: Now Publishers 10(3-4): 145-322

Choi I (2001) Unit root tests for panel data. J Int Money Financ 20:249-272

Christiano LJ, Eichenbaum M, Evans CL (1999) Monetary policy shocks: what have we learned and to what end? In: Taylor JB, Woodford M (eds) Handbook of Macroeconomics, vol 1A. Elsevier, Amsterdam

Christiano LJ, Eichenbaum M, Evans CL (2005) Nominal rigidities and the dynamic effects of a shock to monetary policy. J Polit Econ 113(1):1-45

Compeán RG (2013) The death effect of severe climate variability. Proc Econ Finance 5:182-191

Dell M, Jones BF, Olken BA (2009) Temperature and income: reconciling new cross-sectional and panel estimates. Am Econ Rev 99(2):198-204

Dell M, Jones BF, Olken BA (2012) Temperature shocks and economic growth: evidence from the last half century. Am Econ J Macroecon 4(3):66-95

Deryugina T and Hsiang SM (2014) Does the environment still matter? Temperature and income in the United States. NBER Working Paper No. 20750

Deschenes O (2014) Temperature, human health, and adaptation: a review of the empirical literatures. Energy Econ 46:606-619 
Devlin C, Hendrix CS (2014) Trends and triggers redux: climate change, rainfall, and interstate conflict. Polit Geogr 43:27-39

Dunlap A, Fairhead J (2014) The militarisation and marketisation of nature: an alternative lens to 'climateconflict'. Geopolit 19(4):937-961

Feitelson E, Tubi A (2017) A main driver or an intermediate variable? Climate change, water and security in the Middle East. Glob Environ Chang 44:39-48

Fetzek S, Mazo J (2014) Climate, scarcity and conflict. Survival: Global Politics and Strategy 56(5):37-41

Fomby T, Ikeda Y, Loaza NV (2011) The growth aftermath of natural disasters. J Appl Econ 28(3):412-434

Food and Agricultural Organisation (2018a) Impacts of climate change on fisheries and aquaculture: synthesis of current knowledge, adaptation and mitigation options. FAO Fisheries and Aquaculture Technical Paper No. 627

Food and Agricultural Organization (2018b) AQUASTAT Main Database, Food and Agricultural Organization of the United Nations (FAO). http://www.fao.org/nr/water/aquastat/data/query/index.html?lang=en . Accessed January 2019

Gali J (2008) Monetary policy, inflation and the business cycle. Princeton University Press, Princeton

Gassebner M, Keck A, Teh R (2010) Shaken, not stirred: the impact of disasters on international trade. Int Econ Rev 18(2):351-368

Heinen A, Khandan J, Strobl E (2019) The price impact of extreme weather in developing countries. Econ J R Econ Soc 129(619):1327-1342

Homer-Dixon TF (1999) Environment, scarcity, and violence. Princeton University Press, Princeton and Oxford

Hsiang SM, Jina AS (2014) The causal effect of environmental catastrophe on long-run economic growth: evidence from 6,700 cyclones. National Bureau of Economic Research Working Paper No. 20352

Im K, Pesaran H, Yeongchol S, Shin Y (2003) Testing for unit roots in heterogeneous panel. J Econ 115(1):5374

IPCC (2014) Climate change 2014: Impacts, adaptation and vulnerability. part a: Global and sectoral aspects. Fifth assessment report of the intergovernmental panel on climate change. Cambridge University Press:1-32

Jones BF, Olken BA (2010) Climate shocks and exports. Am Econ Rev: Papers and Proceedings 100:454 459

Kahn ME, Mohaddes K, Ng RNC, Pasaran MH, Raissi M, Yang J-C. (2019) Long-term macroeconomic effects of climate change: a cross-country analysis. Natl Bureau Econ Res. https://www.nber.org/papers/w26167 August 2019. Accessed March10

Kolstad C D and Moore F C (2019) Estimating the economic impacts of climate change using weather observations. NBER Working Paper No. 25537

Laframboise N and Loko B (2012) Natural disasters: mitigating impact, managing risks. IMF Working Paper 12/ 245, Washington: International Monetary Fund

Levin A, Lin C-F, Chu C-S J (2002) Unit root tests in panel data: asymptotic and finite-sample properties. J Econ 108(1):1-24

Maddala GS, Wu S (1999) A comparative study of unit root tests with panel data and a new simple test. Oxf Bull Econ Stat 61(S1):631-652

Mall RK, Gupta A and Sonkar G (2017) Effect of climate change on agricultural crops. In Current developments in biotechnology and bioengineering, crop modification, nutrition, and food production, 23-46. https://doi. org/10.1016/B978-0-444-63661-4.00002-5

Mallick SK, Sousa RM (2013) Commodity prices, inflationary pressures, and monetary policy: evidence from BRICS economies. Open Econ Rev 24(4):677-694

Mankiw G N (2005) "Divine Coincidence" in monetary policy. Economist's View https:/economistsview. typepad.com/economistsview/2005/09/mankiw_discusse.html. Accessed 16 July, 2019

Marchiori L, Maystadt J-F, Schumacher I (2012) The impact of weather anomalies on migration in sub-Saharan Africa. J Environ Econ Manag 63:355-374

Milman A, Arsano Y (2014) Climate adaptation and development: contradictions for human security in Gambella, Ethiopia. Glob Environ Chang 29:349-359

Nelson GC, Rosegrant MW, Palazzo A et al (2010) Food security, farming, and climate change to 2050: scenarios, results, policy options. International Food Policy Research Institute (IFPRI), Washington

Parker M (2018) The impact of disasters on inflation. Econ Disaster Clim Chang 2(1):21-48

Perch-Nielsen SL, Bättig MB, Imboden D (2008) Exploring the link between climate change and migration. Clim Chang 91:375-393

Pesaran M (2007) A simple panel unit root test in the presence of cross-section dependence. J Appl Econ, 22, 265-312

Pesaran and Co. (2019) Long-term macroeconomic effects of climate change: a cross-country analysis. NBER Working Paper No. 26167, Cambridge (2019)

Petris F (2021) Exogeneity in climate econometrics. Energy Econ 96(3):860-872

Piergallini A, Rodano G (2017) A simple explanation of the Taylor rule. J Econ Issues 22:25-35 
Pindyck RS (2013) Climate change policy: what do the models tell us? J Econ Lit 51(3):860-872

Pugatch T (2019) Tropical storm and mortality under climate change. World Dev 117:172-182

Reiling K, Brady C (2015) Climate change and conflict: an annex to the USAID Climate-Resilient Development Framework. Polit Geogr:3-44

Reis R (2018) Central banks going long. Centre for Macroeconomic Discussion Papers CFMDP2018-10. London School of Economics - Department of Economics. http://www.centreformacroeconomics.ac.uk/ Discussion-Papers/2018/CFMDP2018-10-Paper.pdf. Accessed 21 February, 2021

Rigaud KK, Sherbinin A, Jones B et al (2018) Groundswell: preparing for internal climate migration. World Bank, Washington. https://doi.org/10.1596/29461

Rojas-Downing MM, Nejadhashemi AP, Harrigan T et al (2017) Climate change and livestock: impacts, adaptation, and mitigation. Clim Risk Manag 16:145-163

Rosenzweig C, Parry ML (1994) Potential impact of climate change on world food supply. Nature 367:133-138

Schlenker W (2010) Crop responses to climate and weather: cross-section and panel models. In: Lobell DB, Burke MB (eds) Climate change and agriculture: adapting agriculture to a warmer world. Springer Netherlands, Amsterdam, pp 99-108

Schultz KA, Mankin JS (2019) Is temperature exogenous? The impact of civil conflict on the instrumental climate record in sub-Sahara Africa. Am J Polit Sci 63(4):723-739

Stern N (2016) Economics: current climate models are grossly misleading. Nature 530(7591):407-409

Woodward M (2001) The Taylor rule and optimal monetary policy. Am Econ Rev 90:100-104

World Bank (2019) World development indicators, online statistics. Accessed January 2019. https://databank. worldbank.org/source/world-development-indicators

Publisher's note Springer Nature remains neutral with regard to jurisdictional claims in published maps and institutional affiliations. 